\title{
Effect of endobronchial aspirin challenge on inflammatory cells in bronchial biopsy samples from aspirin-sensitive asthmatic subjects
}

\author{
Shuaib Nasser, Pandora E Christie, Rudolf Pfister, Ana R Sousa, Andrew Walls, \\ Michael Schmitz-Schumann, Tak H Lee
}

\begin{abstract}
Background - The aspirin-induced bronchoconstriction in patients with aspirinsensitive asthma is caused by cysteinyl leukotriene release. The cellular source of the leukotrienes is unknown. The inflammatory cell infiltrate in bronchial biopsy samples from seven aspirin-sensitive asthmatic (ASA) subjects and eight non-ASA subjects before and after local challenge with lysine aspirin was therefore examined.

Methods - Using flexible bronchoscopy, airway mucosal biopsy samples were taken and lysine aspirin solution was placed directly onto a carina of the contralateral lung. Twenty minutes later a second series of biopsy samples was taken from the site of the local endobronchial lysine aspirin challenge. The biopsy samples were double immunostained with a rabbit polyclonal antibody to the enzyme 5-lipoxygenase and monoclonal antibodies to mast cells (AA1), neutrophils (NP57), macrophages (EBM11), T lymphocytes (anti-CD3), and total (BMK13) and activated eosinophils (EG2).
\end{abstract}

Results - A decrease in both absolute mast cell numbers staining with mast cell tryptase (AA1) and the percentage of mast cells co-immunostaining with 5-lipoxygenase was seen in the ASA patients after lysine aspirin challenge compared with the nonASA control group. There was also an increase in the numbers of activated eosinophils (EG2) in the ASA subjects compared with the non-ASA group. No changes were observed in the total numbers of macrophages (EBM11), neutrophils (NP57), total eosinophils (BMK13), and T lymphocytes (anti-CD3) after challenge with lysine aspirin.

Conclusions - The decrease in numbers of mast cells staining for tryptase and the increase in activated eosinophils after endobronchial challenge with lysine aspirin may represent degranulation of these cell types, and may be an early event associated with aspirin-sensitive reactions in ASA subjects.

(Thorax 1996;51:64-70)

Keywords: aspirin-sensitive asthma, endobronchial lysine aspirin, mast cells, eosinophils.
Asthmatic patients with sensitivity to aspirin and other non-steroidal anti-inflammatory drugs are often corticosteroid dependent and have accompanying symptoms of rhinosinusitis including rhinorrhoea, nasal congestion, anosmia, loss of taste, and recurrent severe nasal polyposis. ${ }^{1}$ Upon ingestion of aspirin or other cyclo-oxygenase inhibitors, these individuals have increased cysteinyl leukotriene release as detected in the urine, ${ }^{23}$ nasal lavage fluid, ${ }^{45}$ and bronchial lavage fluid $^{6}$ which does not occur in aspirin-tolerant subjects. Inhibition of the synthesis or the action of cysteinyl leukotrienes by a 5-lipoxygenase inhibitor ${ }^{78}$ or leukotriene receptor antagonists ${ }^{910}$ leads to inhibition of the fall in forced expiratory volume in one second $\left(F E V_{1}\right)$ and amelioration of the naso-ocular effects induced by aspirin in aspirin-sensitive patients, strongly supporting the involvement of cysteinyl leukotrienes in this form of asthma. Despite the evidence for the involvement of cysteinyl leukotrienes in aspirin sensitivity, their cellular source is unknown and there are no previous data on the nature of the inflammatory process in the airways of patients with aspirin-sensitive asthma.

We have already examined the basal inflammatory cell infiltrate in bronchial biopsy samples from 12 aspirin-sensitive asthmatic (ASA) subjects and eight non-ASA control individuals ${ }^{11}$ and found no significant difference in the total number of cells staining for 5-lipoxygenase between the two groups. As a percentage of total 5-lipoxygenase immunostaining cells, there were significantly more mast cells and total eosinophils and significantly fewer total macrophages in the bronchial biopsy samples from ASA subjects than from nonASA subjects. The numbers of neutrophils, T lymphocytes, and activated eosinophils were similar for the two groups. The increased numbers of eosinophils and mast cells identified in the bronchial tissue from ASA subjects may be the source(s) of the enhanced cysteinyl leukotriene production observed in these unique individuals.

In order to assess the nature of the cellular population following lysine aspirin provocation, we have now studied the inflammatory cell infiltrate and the cellular expression of 5-lipoxygenase in bronchial biopsy tissues from asthmatic subjects with aspirin sensitivity before and after endobronchial lysine aspirin challenge and have compared the results with those in control non-ASA individuals. 
Table 1 Clinical characteristics of aspirin-sensitive subjects

\begin{tabular}{|c|c|c|c|c|c|c|c|c|}
\hline Subject no. & Sex & Age & Drugs & $\begin{array}{l}F E V_{1} \\
\text { (l) }\end{array}$ & $\begin{array}{l}F E V_{1}(\% \\
\text { predicted) }\end{array}$ & $\begin{array}{l}\text { Threshold dose of lysine } \\
\text { aspirin }(\mathrm{mg} / \mathrm{ml})\end{array}$ & $\begin{array}{l}\text { Skin } \\
\text { test }\end{array}$ & $\begin{array}{l}\text { Eosinophils } \\
\left(10^{3} / \mu l\right)\end{array}$ \\
\hline $\begin{array}{l}1 \\
2 \\
3 \\
4 \\
5 \\
6 \\
7 \\
\text { Mean (SE) }\end{array}$ & $\begin{array}{l}M \\
F \\
M \\
M \\
M \\
F \\
M\end{array}$ & $\begin{array}{l}57 \\
56 \\
39 \\
56 \\
54 \\
26 \\
24 \\
44 \cdot 6(5 \cdot 6)\end{array}$ & $\begin{array}{l}\text { nBDP } \\
\text { BUD, S, T, IB } \\
\text { BDP, S, T, nBUD } \\
\text { BDP, S, IB, F } \\
\text { PRED, BUD, S, T } \\
\text { BDP, S } \\
\text { BUD, nBUD, S }\end{array}$ & $\begin{array}{l}3 \cdot 76 \\
2 \cdot 1 \\
4 \cdot 11 \\
3 \cdot 52 \\
3 \cdot 2 \\
2 \cdot 93 \\
3 \cdot 08 \\
3 \cdot 24(0 \cdot 25)\end{array}$ & $\begin{array}{l}104 \\
91 \\
109 \\
104 \\
93 \\
87 \\
81 \\
95 \cdot 6(3 \cdot 9)\end{array}$ & $\begin{array}{l}25 \\
2 \cdot 5 \\
2 \cdot 5 \\
7 \cdot 5 \\
2 \cdot 5 \\
25 \\
1 \cdot 25 \\
9 \cdot 5(4 \cdot 1)\end{array}$ & $\begin{array}{l}- \\
- \\
+ \\
+ \\
+ \\
+ \\
-\end{array}$ & $\begin{array}{l}0.35 \\
0.39 \\
1.01 \\
0.34 \\
0.36 \\
0.32 \\
0.32 \\
0.44(0.1)\end{array}$ \\
\hline
\end{tabular}

$\mathrm{PRED}=$ prednisolone; $\mathrm{BDP}=$ beclomethasone dipropionate; $\mathrm{BUD}=$ budesonide; $\mathrm{n}=$ nasal route; $\mathrm{S}=$ salbutamol; $\mathrm{T}=$ theophylline; $\mathrm{IB}=$ ipratropium bromide; $\mathrm{F}=$ fenoterol.

Table 2 Clinical characteristics of non-aspirin-sensitive subjects

\begin{tabular}{|c|c|c|c|c|c|c|c|}
\hline $\begin{array}{l}\text { Subject } \\
\text { no. }\end{array}$ & Sex & Age & Drugs & $\begin{array}{l}F E V_{1} \\
\text { (l) }\end{array}$ & $\begin{array}{l}F E V_{I} \\
\text { (\% predicted) }\end{array}$ & $\begin{array}{l}\text { Skin } \\
\text { test }\end{array}$ & $\begin{array}{l}\text { Eosinophils } \\
\left(10^{3} / \mu l\right)\end{array}$ \\
\hline $\begin{array}{l}1 \\
2 \\
3 \\
4 \\
5 \\
6 \\
7 \\
8 \\
\text { Mean (SE) }\end{array}$ & $\begin{array}{l}\mathrm{F} \\
\mathrm{M} \\
\mathrm{M} \\
\mathrm{M} \\
\mathrm{M} \\
\mathrm{M} \\
\mathrm{M} \\
\mathrm{F}\end{array}$ & $\begin{array}{l}53 \\
35 \\
49 \\
34 \\
25 \\
25 \\
30 \\
37 \\
36(3 \cdot 6)\end{array}$ & $\begin{array}{l}\text { BDP, DSCG, R } \\
\text { DSCG, R } \\
\text { BUD, S } \\
\text { S, T, DSCG } \\
\text { IB, F } \\
\text { BUD, IB, F } \\
\text { BDP, S } \\
\text { PRED, BUD, nBUD, S, T }\end{array}$ & $\begin{array}{l}3 \cdot 4 \\
4 \cdot 57 \\
5 \cdot 3 \\
3 \cdot 68 \\
3 \cdot 93 \\
3 \cdot 52 \\
2 \cdot 28 \\
1.59 \\
3 \cdot 81(0 \cdot 36)\end{array}$ & $\begin{array}{l}133 \\
102 \\
126 \\
82 \\
95 \\
78 \\
52 \\
54 \\
90 \cdot 2(10 \cdot 2)\end{array}$ & $\begin{array}{l}- \\
+ \\
+ \\
+ \\
+ \\
+ \\
+ \\
+\end{array}$ & $\begin{array}{l}0 \cdot 14 \\
0 \cdot 41 \\
0 \cdot 23 \\
0 \cdot 29 \\
0 \cdot 92 \\
0 \cdot 08 \\
0 \cdot 46 \\
0 \cdot 19 \\
0 \cdot 34(0 \cdot 13)\end{array}$ \\
\hline
\end{tabular}

PRED = prednisolone; $\mathrm{BDP}=$ beclomethasone dipropionate; $\mathrm{BUD}=$ budesonide; $\mathrm{n}=$ nasal route; $\mathrm{S}=$ salbutamol; $\mathrm{T}=$ theophylline; $\mathrm{IB}=$ ipratropium bromide; $\mathrm{DSCG}=$ disodium cromoglycate; $\mathrm{F}=$ fenoterol; $\mathrm{R}=$ reproterol.

\section{Methods}

SUBJECTS

Two groups of non-smoking asthmatic subjects were studied during their stay at the Hochgebirgsklinik Davos-Wolfgang. Seven ASA subjects (five men) of mean age 44.6 (range 24-57) years with a mean (SE) $\mathrm{FEV}_{1}$ of $95.6(3.9) \%$ predicted values and a control group of eight (six men) non-ASA subjects of mean age 36 (range 25-53) years and a mean $\mathrm{FEV}_{1}$ of $90 \cdot 2$ $(10.2) \%$ predicted values underwent endobronchial lysine aspirin challenge. Of the seven ASA subjects, one took prednisolone orally, six took regular inhaled corticosteroids, and three took regular nasal corticosteroids (table 1). Of the eight non-ASA subjects, one took prednisolone orally, five took regular inhaled corticosteroids, and one subject took regular nasal corticosteroids; three subjects were on no regular glucocorticoid treatment (table 2). All subjects were taking inhaled or oral $\beta_{2}$ agonists as required.

\section{STUDY DESIGN}

The diagnosis of aspirin sensitivity was made on the basis of history and confirmed by a $20 \%$ or greater fall in $\mathrm{FEV}_{1}$ by lysine aspirin inhalation challenge. The non-ASA control subjects also underwent lysine aspirin challenge and, if negative, this was confirmed by incremental oral aspirin challenge to $500 \mathrm{mg}$ aspirin. All subjects were skin prick tested to common aeroallergens and atopy was defined as the presence of at least two positive reactions (a weal $3 \mathrm{~mm}$ greater than saline control) to skin prick tests with the following allergens: cat fur, dog hair, grass pollen, and Dermatophagoides pteronyssinus. Blood was taken for eosinophil count. At least one week after aspirin challenge the patients underwent bronchoscopy and had bronchial biopsy samples taken before and after endobronchial lysine aspirin challenge. The biopsy samples were immediately snap frozen in embedding medium and stored at $-80^{\circ} \mathrm{C}$. Each subject underwent only one endobronchial challenge procedure.

All subjects gave written and informed consent and the study was approved by the Hochgebirgsklinik Davos-Wolfgang ethics committee and performed in accordance with the Helsinki declaration.

\section{LYSINE ASPIRIN INHALATION CHALLENGE}

Measurements of $\mathrm{FEV}_{1}$ were made using a spirometer (Micromedical Ltd, Rochester, Kent, UK). Three recordings of $\mathrm{FEV}_{1}$ were made at each time point and the highest value was used. Lysine aspirin inhalation challenge was performed by the method of SchmitzSchumann and co-workers. ${ }^{12}$ Lysine aspirin (Synthelabopharma, Lausanne, Switzerland), a powder containing $900 \mathrm{mg}$ lysine acetylsalicylate and $100 \mathrm{mg}$ glycine, was diluted in $5 \mathrm{ml}$ water to produce a solution of $180 \mathrm{mg} / \mathrm{ml}$ $(0.55 \mathrm{~mol} / \mathrm{l})$ lysine acetylsalicylate (equivalent to $100 \mathrm{mg} / \mathrm{ml}$ acetylsalicylic acid). This solution was diluted with sodium chloride to produce a range of increasing doubling concentrations from $1.25 \mathrm{mg} / \mathrm{ml}$ to $25 \mathrm{mg} / \mathrm{ml}(3.8 \mathrm{mmol} / 1$ to $76 \cdot 1 \mathrm{mmol} / \mathrm{l}$ ). Nebulised solutions of $1 \mathrm{ml}$ lysine aspirin were administered at room temperature using a Heyer nebuliser (Carl Heyer $\mathrm{GmbH}$, Bad Ems, Germany). Delivery of air to the nebuliser was regulated to an output of $81 / \mathrm{min}$ and under these conditions the nebuliser delivers droplets with a mass median aerodynamic diameter of $5 \mu \mathrm{m}$. After baseline measurements of $\mathrm{FEV}_{1}$, the subjects inhaled the aerosol via a mouthpiece during normal tidal breathing. If the decrease in $\mathrm{FEV}_{1}$ following nebulised normal saline was $<10 \%$ the subjects underwent lysine aspirin challenge. Incremental doubling concentrations of lysine aspirin were used for bronchial challenge at 30 minute intervals, with $\mathrm{FEV}_{1}$ measurements at 
15 and 30 minutes until a fall in $\mathrm{FEV}_{1}$ of at least $20 \%$ was achieved (threshold concentration of lysine aspirin). A fall in $\mathrm{FEV}_{1}$ of between $10 \%$ and $20 \%$ was allowed to return to within $10 \%$ of baseline before further lysine aspirin administration. Further measurements of $\mathrm{FEV}_{1}$ were continued for at least four hours after a positive reaction and salbutamol was administered if necessary.

\section{BRONCHOSCOPY}

Bronchoscopies were all performed at the same time of day ( 08.00 hours) and by the same individual in accordance with current working party guidelines. ${ }^{13}$ Thirty minutes before the procedure all patients received $1.25 \mathrm{mg}$ salbutamol by nebulisation. After premedication with $0.5 \mathrm{mg}$ atropine intramuscularly, $10 \mathrm{mg}$ diazepam orally, and topical preservative-free $2 \%$ lignocaine, a fibreoptic bronchoscope (Olympus model BF-IT20D, Tokyo, Japan) was inserted orally and two or three mucosal biopsy samples were taken using non-toothed forceps from a right middle or lower lobe segmental carina. Supplemental oxygen was supplied via a nasal cannula at $41 / \mathrm{min}$ throughout the procedure and pulse and arterial oxygen saturation were monitored using a pulse oximeter. After endobronchial challenge with lysine aspirin via the bronchoscope the instrument was removed. It was re-introduced 20 minutes later after additional local anaesthesia, if necessary. Further biopsy samples were taken from the sites of the endobronchial challenges in the left lung. All subjects were monitored clinically during and for four hours after the procedure with measurements of $\mathrm{FEV}_{1}$ and to allow recovery from the sedation.

\section{ENDOBRONCHIAL LYSINE ASPIRIN CHALLENGE}

One millilitre of a solution of lysine aspirin corresponding to the threshold concentration was drawn into a soft plastic catheter and introduced into the bronchoscope. The catheter tip was first positioned on the carina between the lingula and the upper division bronchus and then on the carina of the left upper lobe. At each of the two sites one drop $(20 \mu \mathrm{l})$ of lysine aspirin solution, at the previously determined threshold concentration, was placed gently on the carina and dispersed by lateral movements of the instrument without touching the bronchial mucosa. In the non-ASA subjects the same protocol was followed but the maximum challenge concentration of $25 \mathrm{mg} / \mathrm{ml}$ lysine aspirin was used. No previous reports of endobronchial lysine aspirin challenge were available and we therefore performed the challenge in two ASA and two non-ASA subjects in preliminary studies, in the manner described above. Immunohistochemical analyses of the biopsy samples, carried out in a blinded manner, revealed that this dose of lysine aspirin elicited an apparent increase in the number of cells staining with 5-lipoxygenase in ASA subjects compared with baseline. There were no changes in the two control non-ASA biopsy samples.

\section{ANTIBODIES}

The antibody to the enzyme 5-lipoxygenase was a rabbit polyclonal (kindly donated by J Evans, Merck Frosst Laboratories, Dorval, Quebec, Canada) and used at a dilution of 1/ 1000. All the primary antibodies used for cell identification were mouse monoclonal $\mathrm{IgG}_{1}$ antibodies and comprised the following: AA1 (Dako, High Wycombe, UK), a mast cell tryptase marker used at a dilution of 1/50; EBM11 (Dako), a pan-macrophage marker recognising CD68 used at $1 / 100$ dilution; anti-CD3 (Dako), a pan-T lymphocyte marker used at 1/50 dilution; NP57 (Dako), an anti-human neutrophil elastase antibody used at 1/600 dilution; BMK13 (Cymbus Bioscience Ltd, Chilworth, UK), a pan-eosinophil marker recognising major basic protein used at 1/40 dilution; EG2 (Kabi Pharmacia, Milton Keynes, UK) which detects secreted eosinophil cationic protein and therefore is a marker for activated eosinophils and was used at $1 / 100$ dilution. The secondary antibodies were a goat anti-mouse alkaline phosphatase conjugated antibody (Sera-lab, Crawley Down, UK) and used at a dilution of $1 / 100$, and a swine antirabbit biotinylated antibody used at a dilution of $1 / 200$.

\section{IMMUNOSTAINING}

The bronchial biopsy samples were immediately mounted in OCT and snap frozen using isopentane $(\mathrm{BDH})$ cooled down in liquid nitrogen (Bayer, Basingstoke, UK). The samples were stored at $-80^{\circ} \mathrm{C}$ until further analysis. Sections $5 \mu \mathrm{m}$ thick were cut from frozen bronchial biopsy samples onto slides coated with 3-aminopropyltriethoxy-silane (Sigma, Dorset, UK) to improve adhesion. ${ }^{14}$ The sections were cut from the centre of the biopsy sample to ensure as large a cross sectional area as possible for immunostaining. They were then fixed in acetone and stored at $-70^{\circ} \mathrm{C}$ until used for immunohistochemistry. One section was examined for each cell marker. The biopsy samples were double immunostained using a rabbit polyclonal antibody to the enzyme 5-lipoxygenase concurrently with one monoclonal antibody to each cell type: neutrophils (NP57); macrophages (EBM11); total (BMK13) and degranulated eosinophils (EG2); mast cells (AA1), and T lymphocytes (anti-CD3). Immunohistochemical analysis was carried out using both indirect avidinbiotin complex and alkaline phosphatase antialkaline phosphatase techniques. Endogenous biotin activity was abolished by incubating the sections with $0.01 \%$ avidin for 10 minutes followed by $0.01 \%$ biotin for 10 minutes. Each section was then treated with $1 / 10$ normal swine serum (Dako) for 10 minutes to block nonspecific sites. The section was then incubated with a mixture of the anti-5-lipoxygenase and one of each of the cell marker primary antibodies for 90 mintues at room temperature. This was followed by incubation with $1 / 200$ biotinylated swine anti-rabbit and 1/100 alkaline phosphatase conjugated goat anti-mouse secondary antibody for 45 minutes. Endo- 
genous peroxidase activity was abolished by incubation with a mixture of $10 \mathrm{mM}$ glucose with $0.065 \mathrm{mg} / \mathrm{ml}$ sodium azide and $1 \mu \mathrm{g} / \mathrm{ml}$ glucose oxidase for 30 minutes at $37^{\circ} \mathrm{C}^{15}$ Avidin-biotin complex (Dako) was prepared according to the manufacturer's instructions and incubated on the sections for 30 minutes. The immunoperoxidase colour reaction was developed by incubation for five minutes with diaminobenzidine $(0.75 \mathrm{mg} / \mathrm{ml})$ and hydrogen peroxide $\left(30 \mu \mathrm{l} 0 \cdot 1 \% \mathrm{H}_{2} \mathrm{O}_{2} / \mathrm{ml}\right)$. This was followed by a 15 minute incubation with alkaline phosphatase buffer containing $100 \mathrm{mM}$ aminomethylpropanediol, $1 \mathrm{mM}$ magnesium sulphate, and $1 \mathrm{mM}$ magnesium sulphate, and $1 \mathrm{mM}$ levamisole to block the endogenous alkaline phosphatase activity of bronchial tissue. The alkaline phosphatase reaction was developed by incubation with 5-bromo-4-chloro3-indolyl phosphate/nitroblue tetrazolium (Sigma) for 15 minutes in the dark. The sections were counterstained with methyl green for two minutes and then mounted permanently in DPX (BDH) after dehydrating first in incremental concentrations of ethanol followed by acetone and toluene. A positive control using nasal polyp tissue and a negative control without primary antibody was included in each staining run.

\section{QUANTITATION OF CELL NUMBER}

The cell counts were performed by a single individual who was blinded to the aspirin sensitivity status of the patients. The total number of positive staining cells in the whole of the subepithelium was counted. The intra-observer coefficient of variation for cell counts was consistently less than $11 \%$ as calculated from repeated counting of 10 sections. The huesaturation-intensity (HSI) system of colour image analysis ${ }^{16}$ was used in the measurements of the subepithelial area of the biopsy sample. This was performed on an image analyser consisting of a PC computer containing colour image processing boards (Data Translation, Marlboro, MA, USA) with colour Freelance software (Slight Systems, Hove, UK). The colour image was acquired from the microscope via a JVC 3 chip colour TC camera. The HSI thresholds for the tissue were programmed into the computer. The subepithelial area was then outlined manually by the use of a mouse facility in the software. Automatic detection of the tissue was performed within this manually defined zone and the computer calculated a numerical value for the area of tissue measured (in $\mathrm{mm}^{2}$ ). From a knowledge of the cell number and area, the number of positive staining cells was calculated in each biopsy sample and for each cell type. The area of the biopsy samples ranged from 0.3 to $1 \mathrm{~mm}^{2}$.

\section{DATA ANALYSIS}

Results are presented as mean (SE). Statistical analyses were performed with SPSS for Windows. A figure for the difference in cell numbers per $\mathrm{mm}^{2}$ and the percentage of total 5-lipoxygenase positive cells co-immunostaining with each cell type was calculated before and after endobronchial lysine aspirin challenge and compared between ASA and non-ASA groups using the Mann-Whitney $U$ non-parametric test for independent samples.

\section{Results}

SUBJECTS

The baseline characteristics of the two groups of subjects are presented in tables 1 and 2 . There were no significant differences in $\mathrm{FEV}_{1}$ between the ASA and non-ASA subjects, and no statistical differences in peripheral blood eosinophil count were seen between the two groups. Four of the seven ASA subjects and six of the eight non-ASA subjects were skin prick test positive to the aeroallergens tested. Bronchoscopy, endobronchial lysine aspirin challenge, and bronchial biopsy were well tolerated by all individuals and there were no adverse effects.

\section{CELL NUMBERS}

After endobronchial challenge there was a decrease in mast cell numbers staining for mast cell tryptase in the ASA subjects challenged with lysine aspirin from $30.4(11 \cdot 1) / \mathrm{mm}^{2}$ to $14 \cdot 1(8 \cdot 6) / \mathrm{mm}^{2}$, and this change was significantly different $(p<0.05)$ from the change in the non-ASA subjects (fig 1, table 3 ).

The number of total eosinophils (BMK13) in the ASA group was $148 \cdot 6(28 \cdot 1) / \mathrm{mm}^{2}$ before and $171(40) / \mathrm{mm}^{2}$ after challenge with lysine aspirin, which did not represent a significant difference from the change in the non-ASA group. There was an increase in EG2 positive eosinophils in six of the seven ASA subjects after lysine aspirin challenge, whereas only one non-ASA subject demonstrated an increase in the numbers of EG2 positive cells after challenge. The change in the numbers of EG2

Table 3 Mean (SE) cell numbers per $\mathrm{mm}^{2}$ for each cell marker before and after local endobronchial challenge with lysine aspirin in aspirin-sensitive asthmatic (ASA) and non-ASA subjects

\begin{tabular}{|c|c|c|c|c|c|c|c|c|c|c|c|c|}
\hline & \multicolumn{2}{|c|}{$\begin{array}{l}\text { Mast cells staining for } \\
\text { tryptase }(A A 1)^{*}\end{array}$} & \multicolumn{2}{|c|}{$\begin{array}{l}\text { Total eosinophils } \\
\text { (BMK) }\end{array}$} & \multicolumn{2}{|c|}{$\begin{array}{l}\text { Activated eosinophils } \\
(E G 2)^{*}\end{array}$} & \multicolumn{2}{|l|}{$\begin{array}{l}\text { Macrophages } \\
\text { (EBM11) }\end{array}$} & \multicolumn{2}{|l|}{$\begin{array}{l}\text { Neutrophils } \\
\text { (NP57) }\end{array}$} & \multicolumn{2}{|c|}{$\begin{array}{l}\text { T lymphocytes } \\
\text { (anti-CD3) }\end{array}$} \\
\hline & Before & After & Before & After & Before & After & Before & After & Before & After & Before & After \\
\hline \multirow{2}{*}{$\begin{array}{l}\text { ASA } \\
\text { subjects } \\
\text { Non-ASA } \\
\text { subjects }\end{array}$} & $30 \cdot 4(11 \cdot 1)$ & $14 \cdot 1(8 \cdot 6)$ & $149(28 \cdot 1)$ & $171(40)$ & $28 \cdot 3(25 \cdot 3)$ & $31 \cdot 7(9 \cdot 7)$ & $106(39 \cdot 1)$ & $85.4(30 \cdot 7)$ & $132(73)$ & $235(73 \cdot 3)$ & $76 \cdot 9(38 \cdot 4)$ & $105(41 \cdot 4)$ \\
\hline & $10 \cdot 6(8 \cdot 7)$ & $4 \cdot 1(2)$ & $59 \cdot 4(20)$ & $115(45)$ & $26 \cdot 4(15)$ & $6 \cdot 4(5 \cdot 4)$ & $169(44)$ & $52 \cdot 8(13 \cdot 1)$ & $117(39 \cdot 5)$ & $185(57 \cdot 9)$ & $91 \cdot 1(64 \cdot 8)$ & $37(17 \cdot 6)$ \\
\hline
\end{tabular}

${ }^{*} \mathrm{p}<0.05$ when the changes before and after lysine aspirin challenge in ASA subjects are compared with non-ASA subjects. 
A

AA1 (mast cells)

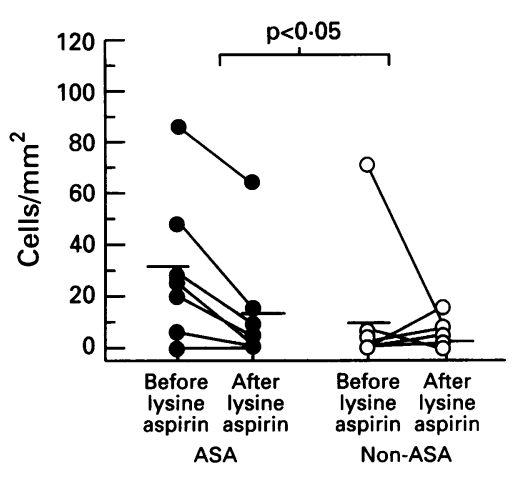

D

EBM11 (macrophages)

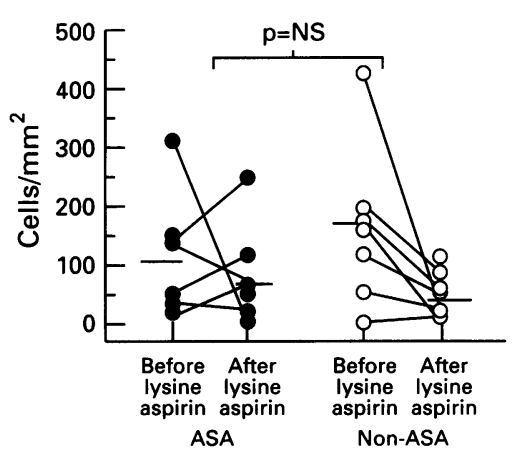

BMK13 (total eosinophils)

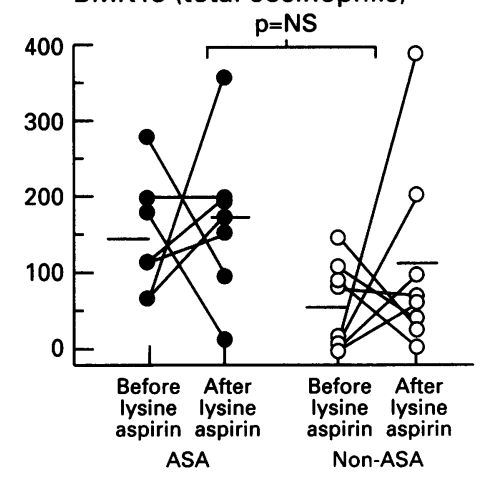

E

NP57 (neutrophils)

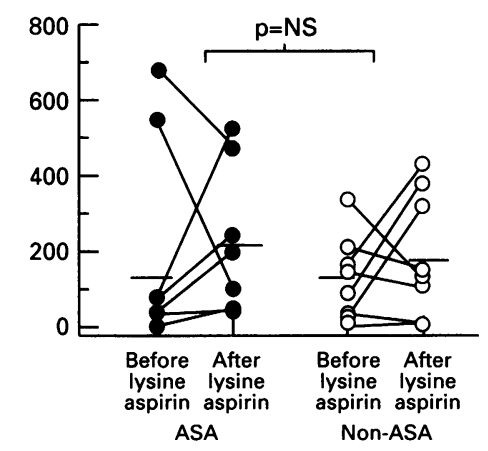

EG2 (activated eosinophils)

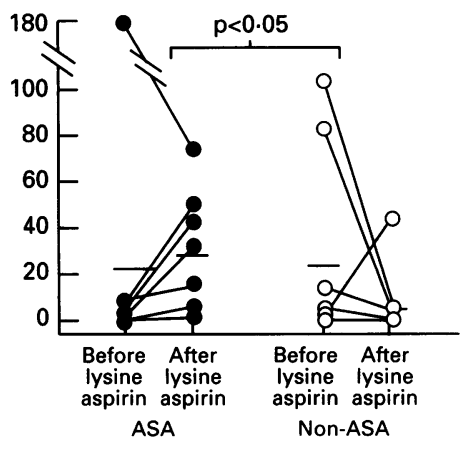

$F$

Anti-CD3 (T lymphocytes)

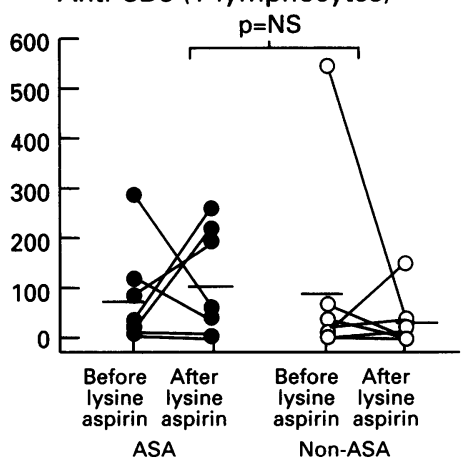

Figure 1 Results obtained from seven aspirin-sensitive asthmatic (ASA) and eight non-ASA subjects both before and after endobronchial challenge with lysine aspirin. Total number of cells/mm ${ }^{2}$ of bronchial biopsy tissue identified immunohistochemically as $(A)$ mast cells (AA1); (B) total eosinophils (BMK13); (C) degranulated eosinophils (EG2); (D) macrophages (EBM11); (E) neutrophils (NP57); (F) T lymphocytes (anti-CD3). Means are represented by a horizontal bar.

positive cells in the ASA group was significantly different from the non-ASA subjects $(p<0.05)$.

Compared with the non-ASA group, there was no significant change in numbers of macrophages, neutrophils, or $\mathrm{T}$ lymphocytes in the ASA group after challenge with lysine aspirin.

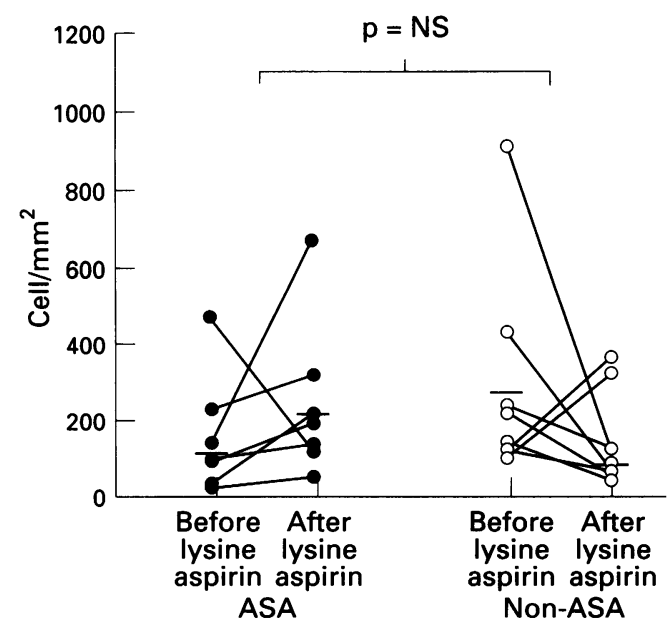

Figure 2 Total number of cells $/ \mathrm{mm}^{2}$ staining for 5lipoxygenase in bronchial biopsy tissue obtained from seven aspirin-sensitive asthmatic ( $A S A$ ) and eight non- $A S A$ subjects both before and after endobronchial challenge with lysine aspirin. Means are represented by a horizontal bar.
CELLS STAINING FOR 5-LIPOXYGENASE

Before endobronchial challenge the total numbers of cells immunostaining for 5-lipoxygenase in the bronchial bronchial biopsy samples from the seven ASA subjects were similar to those in biopsy samples from the non-ASA control subjects (fig 2). After endobronchial challenge there was no significant change in the numbers of 5-lipoxygenase staining cells in the ASA subjects compared with the change in the nonASA subjects.

The percentage of 5-lipoxygenase positive cells co-immunostaining with the mast cell marker AA1 decreased from $14 \cdot 7(5 \cdot 1) \%$ to 5 $(2 \cdot 3) \%$ in the ASA group after endobronchial lysine aspirin challenge which was significantly different $(\mathrm{p}<0.05)$ from the change in the nonASA group $(3 \cdot 4(3 \cdot 1) \%$ to $2 \cdot 3(1 \cdot 0) \%)$.

The percentage of 5-lipoxygenase positive cells co-immunostaining for eosinophils (BMK13) was not significantly different between the ASA and non-ASA groups. However, the percentage of 5-lipoxygenase positive cells co-immunostaining for activated eosinophils (EG2) increased following challenge with lysine aspirin in five ASA individuals and in only one non-ASA subject; this difference was significantly different $(p<0 \cdot 05)$.

There were no significant changes in the percentage of 5-lipoxygenase positive cells co- 
immunostaining with other cell types. $T$ lymphocytes (anti-CD3) did not co-immunostain with 5-lipoxygenase.

\section{Discussion}

This study shows that 20 minutes after endobronchial challenge with lysine aspirin solution in ASA individuals there was a significant reduction in the number of mast cells and an increase in the number of activated eosinophils that was not observed in the non-ASA subjects. There is no previous study reporting endobronchial lysine aspirin challenge in aspirin sensitive patients. The timing of the biopsy was determined by the maximal bronchoconstrictor reaction after inhalation of lysine aspirin solution which normally occurs at the same time following challenge. We used the concentration of lysine aspirin for endobronchial challenge in each ASA individual which had already been found to cause a $20 \%$ reduction in $\mathrm{FEV}_{1}$ when inhaled (the threshold concentration) by the same subject. For the non-ASA subjects the highest concentration of $25 \mathrm{mg} / \mathrm{ml}$ was used. We reasoned that the total dose in $20 \mu \mathrm{l}$ applied locally via the bronchoscope was probably substantially greater than the dose which would have deposited at the same location following nebulised inhalation of the same concentration of lysine aspirin solution. The application of higher concentrations of lysine aspirin locally may have induced more profound changes in inflammatory cell populations.

We have used well characterised antibodies for the definition of different inflammatory cells by immunohistochemistry. The 5-lipoxygenase antibody used in the study was raised against purified human leucocyte 5-lipoxygenase and its specificity is indicated by immunoblot recognition of both rat and human leucocyte 5lipoxygenase at dilutions of $1: 200$ and by its ability to immunoprecipitate human leucocyte 5-lipoxygenase using standard western analysis. A study of the immunolocalisation of 5-lipoxygenase to the nuclear envelope has recently been published utilising this rabbit polyclonal antibody. ${ }^{17}$ Mast cells were identified using an antibody against tryptase, clone AA1, which is a commercially available mouse monoclonal product and recognises mast cell tryptase specifically in the concentrations used in this study.

It was surprising to find that there was a decrease in the number of cells staining with the anti-tryptase antibody following lysine aspirin provocation, because previous work in allergen challenge in vitro has indicated that mast cell degranulation is incomplete and that there should still be substantial tryptase left within the cell. However, no previously published study has reported on the mast cell appearances using the antibody AAl after either in vivo allergen or aspirin challenges. Furthermore, mast cell tryptase is a water soluble complex, and because cryosections were used in this study, it is possible that during the immunostaining procedure tryptase from degranulated mast cells may have washed away. Thus, the apparent decrease in mast cell numbers found in this study can be explained by the presence of degranulated "phantom" mast cells.

There are several possible explanations for the apparent decrease in mast cell numbers other than substantial degranulation. These include the possibility that the ability to detect mast cells in some of the samples failed for technical reasons. This seems unlikely because it only occurred in ASA individuals after lysine aspirin challenge and there was no significant change in the non-ASA subjects. The results may be explained by the migration of mast cells out of the subepithelium after challenge. However, the time between biopsies was too short for this to have occurred and therefore this possibility also seems unlikely. Finally, lysine aspirin challenge in ASA patients may have produced an element of mucosal oedema which would result in a decrease in the density of all cells counted in the biopsy samples taken after the challenge. However, the numbers of most of the cells did not change and, indeed, the numbers of EG2 positive eosinophils increased. Therefore, the most likely explanation for our results is that there was considerable localised mast cell degranulation.

There is substantial evidence from the literature to support the concept for mast cell degranulation in aspirin-induced reactions in sensitive individuals. For instance, immunohistochemical examination of nasal polyps obtained from ASA patients demonstrated abundant eosinophils and degranulated mast cells. ${ }^{18}$ Bosso and colleagues have reported increased serum histamine and tryptase levels after aspirin ingestion in some ASA subjects who manifest moderate to severe respiratory reactions associated with aspirin-induced reactions in other organs. ${ }^{19}$ Similarly, Ferreri found increased levels of $\mathrm{LTC}_{4}$ and histamine in nasal secretions associated with decreases in $\mathrm{FEV}_{1}$ in three out of four ASA patients. ${ }^{5}$ In $5-10 \%$ of patients with systemic mast cell disease aspirin therapy causes massive mast cell mediator release with an anaphylactoid reaction, suggesting that aspirin can directly release mast cell mediators in certain subjects. ${ }^{20}$ Treatment with cromolyn sodium in 20 subjects with aspirin sensitive asthma has been reported to lead to a $17 \%$ improvement in $\mathrm{FEV}_{1} 50$ minutes after inhalation. ${ }^{21}$ Furthermore, pretreatment with cromolyn sodium either prevented or delayed asthmatic responses to aspirin ingestion. ${ }^{22}$ The demonstration that a putative mast cell mediator, high molecular weight neutrophil chemotactic factor, was released into the serum of half of 22 subjects following aspirin-induced asthmatic reactions lends further support to the concept of mast cells as the source of mediators responsible for reactions in patients with aspirinsensitive asthma. ${ }^{23}$ In a separate study the release of neutrophil chemotactic factor was abolished after desensitisation to aspirin in 10 subjects with aspirin-induced urticaria. ${ }^{24} \mathrm{Re}$ cently, Fischer and colleagues have reported a significant rise in nasal lavage mast cellderived tryptase levels following aspirin ingestion in ASA subjects, ${ }^{25}$ thereby providing direct evidence for mast cell degranulation. 
The other important finding from this study was the increased numbers of activated eosinophils in six out of seven subjects following challenge with lysine aspirin which was not seen in the non-ASA group. Consistent with this is the absence of an increase in total eosinophil numbers. This suggests that either aspirin itself or some other factor, perhaps mast cell-derived, activates existing eosinophils in the airways of patients with ASA. There is substantial support for eosinophil activation in ASA reactions. Sladek and colleagues found increased eosinophils and release of extracellular protein (ECP) in bronchoalveolar lavage fluid of subjects with ASA compared with control individuals. ${ }^{6}$ The same authors also reported a significant fall in peripheral blood eosinophil numbers and a rise in serum ECP and tryptase following oral aspirin ingestion in ASA subjects, implicating both mast cells and eosinophils in this reaction. ${ }^{26}$ In a study of seven subjects with ASA, Yoshimi and colleagues reported an increased peripheral blood eosinophilia and increased numbers of activated eosinophils in nasal polyps of these patients. ${ }^{27}$

The total number of cells expressing 5-lipoxygenase was the same in ASA subjects and the controls, both at baseline and after lysine aspirin challenge. Thus, although the 5-lipoxygenase pathway is upregulated in ASA, this is not due to increased total numbers of 5-lipoxygenase protein-containing cells.

In conclusion we suggest that aspirin challenge in ASA subjects degranulates mast cells and eosinophils, either directly or indirectly via the release of a secondary mediator. Either one or both of these cell types may be responsible for the increased synthesis of cysteinyl leukotrienes found at rest and following aspirin provocation in aspirin intolerance.

This study was supported by the National Asthma Campaign.

1 Samter M, Beers RF. Intolerance to aspirin: clinical studies and consideration of its pathogenesis. Ann Intern Med 1968;68:975-83.

2 Christie PE, Tagari P, Ford-Hutchinson AW, Charlesson S, Chee $\mathrm{P}$, Arm JP, et al. Urinary leukotriene $\mathrm{E}_{4}$ concentrations increase after aspirin challenge in aspirinsensitive asthmatic subjects. Am Rev Respir Dis 1991;143: 1025-9.

3 Christie PE, Tagari P, Ford-Hutchinson AW, Black C, Markendorf A, Lee TH. Urinary leukotriene $\mathrm{E}_{4}$ after lysine-aspirin inhalation in asthmatic subjects. $\mathrm{Am} \mathrm{Rev}$ Respir Dis 1992;146:1531-4.

4 Ortolani C, Mirone C, Fontana A, Folco GC, Miadonna A, Montalbetti N, et al. Study of mediators of anaphylaxis in nasal fluids after aspirin and sodium metabisulfite nasal provocation in intolerant rhinitic patients. Ann Allergy provocation in into

5 Ferreri NR, Howland WC, Stevenson DD, Spiegelberg HL. Release of leukotrienes, prostaglandins, and histamine into nasal secretions of aspirin-sensitive asthmatics during reaction to aspirin. Am Rev Respir Dis 1988;137:847-54.
6 Sladek K, Dworski R, Soja J, Sheller JR, Nizankowska E, Oates JA. Eicosanoids in bronchoalveolar lavage fluid of aspirin-intolerant patients with asthma after aspirin challenge. Am F Respir Crit Care Med 1994;149:940-6.

7 Israel E, Fischer AR, Rosenberg MA, Lilly CM, Callery JC, Shapiro J, et al. The pivotal role of 5-lipoxygenase products in the reaction of aspirin-sensitive asthmatics to aspirin. Am Rev Respir Dis 1993;148:1447-51.

8 Nasser SM, Bell GS, Foster S, Spruce KE, MacMillan R, Williams AJ, et al. Effect of the 5-lipoxygenase inhibitor ZD2138 on aspirin-induced asthma. Thorax 1994;49:74956.

9 Christie PE, Smith CM, Lee TH. The potent and selective sulfidopeptide leukotriene antagonist, SK\&F 104353, insulfidopeptide leukotriene antagonist, SK\&F 104353, in-
hibits aspirin-induced asthma. Am Rev Respir Dis 1991; hibits aspirin-

10 Dahlen B, Kumlin M, Margolskee DJ, Larsson C, Blomqvist $\mathrm{H}$, Williams VC, et al. The leukotriene-receptor antagonist MK-0679 blocks airway obstruction induced by inhaled lysine-aspirin in aspirin-sensitive asthmatics. Eur Respir $\mathcal{F}$ 1993;6:1018-26.

11 Nasser SM, Pfister R, Christie PE, Sousa AR, Barker J, Schmitz-Schumann M., et al. Inflammatory cell populations in bronchial biopies from aspirin-sensitive asthmatic subjects. Am $f$ Respir Crit Care Med 1995;151:A37.

12 Schmitz-Schumann M, Schaub E, Virchow C. Inhalation provocation test with lysine-acetylsalicylic acid in patients provocation test with lysine-acetylsalicylic acid in patients
with analgetics-induced asthma. Prax Klin Pneumol 1982; w6:17-21.

13 Anonymous. Investigative use of bronchoscopy, lavage and bronchial biopsies in asthma and other airways disease. $\mathcal{F}$ Invest Allergol Clin Immunol 1991;1:271-7.

14 Maddox PH, Jenkins D. 3-Aminopropyltriethoxysilane (APES): a new advance in section adhesion. $\mathcal{F}$ Clin Pathol 1987;40:1256-7.

15 Andrew SM, Jasani B. An improved method for the inhibition of endogenous peroxidase non-deleterious to lymphocyte surface markers. Application to immunoperoxidase studies on eosinophil-rich tissue preparations. Histochem $\mathcal{f}$ 1987;19:426-30.

16 Poston RN, Gall NP. Hue saturation (HSI) colour image analyses for the quantification of immunoperoxidase stains. In: Hilger A, ed. Micro 90. New York: Elder, HY, 1990:525-8.

17 Woods JW, Evans JF, Ethier D, Scott S, Vickers PJ, Hearn L, et al. 5-lipoxygenase and 5-lipoxygenase-activating protein are localized in the nuclear envelope of activated human leukocytes. f Exp Med 1993;178:1935-46.

18 Yamashita T, Tsuji H, Maeda N, Tomoda K, Kumazawa $T$. Etiology of nasal polyps associated with aspirin-sensitive asthma. Rhinology 1989;8(Suppl):15-24

19 Bosso JV, Schwartz LB, Stevenson DD. Tryptase and histamine release during aspirin-induced respiratory reactions. $\mathcal{F}$ Allergy Clin Immunol 1991;88:830-7.

20 Yocum MW, Butterfield JH, Gharib H. Increased plasma calcitonin levels in systemic mast cell disease. Mayo Clin Proc 1994;69:987-90.

21 Imokawa S, Sato A, Taniguchi M, Toyoshima M, Nakazawa $\mathrm{K}$, Hayakawa $\mathrm{H}$. Sodium cromoglycate nebulized solution has an acute bronchodilative effect in patients with aspirinintolerant asthma (AIA). Arerugi (fapanese fournal of Allerintolerant asthma (AIA). A
gology) 1992;41:1515-20.

22 Martelli NA, Usandivaras G. Inhibition of aspirin-induced bronchoconstriction by sodium cromoglycate inhalation. Thorax 1977;32:684-90.

23 Szmidt M, Grzelewska-Rzymowska I, Rozniecki J, Grzegorczyk J, Neutrophil chemotactic activity after administration of aspirin during tolerance in patients with asthma and aspirin hypersensitivity. Pneumonologia $i$ Alergologia Polska 1991;59:16-21.

24 Grzelewska-Rzymowska I, Szmidt M, Rozniecki J, Grzegorczyk J. Aspirin-induced neutrophil chemotactic activity (NCA) in patients with aspirin-sensitive urticaria after desensitization to the drug. $\mathcal{F}$ Invest Allergol Clin Immunol 1994;4:28-31.

25 Fischer AR, Rosenberg MA, Lilly CM, Callery JC, Rubin $P$, Cohn J, et al. Direct evidence for a role of the mast cell in the nasal response to aspirin in aspirin-sensitive asthma. in the nasal response to aspirin in aspirin-sent

26 Sladek K, Szczeklik A. Cysteinyl leukotrienes overproduction and mast cell activation in aspirin-provoked bronchospasm in asthma. Eur Respir $\mathcal{F}$ 1993;6:391-9.

27 Yoshimi R, Takamura H, Takasaki $\mathrm{K}$, Tsurumoto $\mathrm{H}$, Kumagami $H$. Immunohistological study of eosinophilic infiltration of nasal polyps in aspirin-induced asthma. Nippon fibiinkoka Gakkai Kaiho 1993;96:1922-5. 